Postoperative Epidural Analgesia between 0.25\%

Ropivacaine Plus Tramadol and 0.25\% Bupivacaine Plus

Tramadol in Abdominal and Lower Limb Surgeries - A

\title{
Comparative Study
}

\author{
Shilpashri AM1*, Lakshmi DD22, Priya $\mathbf{R}^{3}$ and Akash JS ${ }^{3}$ \\ ${ }^{1}$ Professor, Department of Anesthesiology, JJM Medical College, India \\ ${ }^{2}$ Senior Resident, Department of Anesthesiology, JJM Medical College, India \\ 3Junior Resident, Department of Anesthesiology, JJM Medical College, India
}

\section{Research Article \\ Volume 4 Issue 2}

Received Date: June 27, 2019

Published Date: July 18, 2019

*Corresponding author: Shilpashri AM, Associate Professsor, Department of Anesthesiology, JJM Medical College, Davangere, Karnataka-577004, India, Email: shilpashri.am@gmail.com

\section{Abstract}

Background: The treatment of acute postoperative pain is important for modern health services. Analgesia through epidural route appears to have a brighter prospect these days. Local anesthetics like bupivacaine and ropivacaine given in epidural space have helped in successful postoperative pain management. Addition of opioids to local anesthetics has a synergistic action on analgesia.

Objective: To compare analgesic efficacy of Bupivacaine and Ropivacaine in combination with Tramadol for postoperative epidural analgesia in terms of the quality of analgesia, its duration of action and side effects involved.

Materials and methods: 50 patients of age 18-60 years with American Society of Anesthesiologists grade I \& II, undergoing elective abdominal and lower limb surgeries were randomly allotted to each of the 2 groups. Group BT received $0.25 \%$ bupivacaine + tramadol $(1 \mathrm{mg} / \mathrm{kg})$ and group $\mathrm{RT}$ received $0.25 \%$ ropivacaine + tramadol $(1 \mathrm{mg} / \mathrm{kg})$ epidurally. Patients were monitored for onset, duration and quality of analgesia, cardiorespiratory stability and for any side effects or motor blockade.

Results: The mean time of onset of analgesia and quality of analgesia were comparable between the two groups. The duration of action in group RT (417.20 \pm 42.52 mins) was found significantly prolonged than group BT (356.00 \pm 49.03 mins) with $p<0.001$. Significant fall in blood pressures was seen in group BT when compared with group RT. 4 patients in group BT had motor blockade while none in group RT. There were no significant side effects in both the groups. 


\section{Anaesthesia \& Critical Care Medicine Journal}

Conclusion: In our study, we found that Ropivacaine with Tramadol as epidural postoperative analgesia provided equal and effective analgesia when compared to Bupivacaine with Tramadol, but for longer duration and with minimal cardiovascular depression and no motor blockade.

Keywords: Bupivacaine; Tramadol; Postoperative analgesia; Epidural analgesia

\section{Introduction}

A patient's problem with pain does not end with surgical procedure. Pain during postoperative period is a cause of concern not only for the patient, but also for the surgeon and the anesthesiologist. The treatment of acute postoperative pain is important for modern health services. Effective postoperative analgesia decreases the incidence of respiratory and cardiovascular complications, and helps in early return of gastrointestinal motility, early ambulation and discharge from hospital. Inadequate control of postoperative pain may result in increased postoperative morbidities and worsened patient oriented outcomes [1]. Analgesia through epidural route with various drugs has been tried [2-6].

Local anaesthetics like Bupivacaine have been used as the mainstay for epidural analgesia, but motor block and significant cardio-toxicity have remained vital issues. Ropivacaine has recently been introduced into clinical practice in India with a better safety profile. Besides, Ropivacaine does not possess significant motor block, thus providing pain relief without hindering early ambulation [7-13]. Opioids added in low doses to local anaesthetics as adjuvant increases the duration of analgesia, thus sub serving the need for repeated top-ups $[14,15]$.

Unfortunately, the potent opioids like remifentanyl, alfentanyl, sufentanyl or fentanyl which are commonly used in combination with bupivacaine for epidural anesthesia are not available even in many tertiary care hospitals. So, easily available and comparatively potent opioid tramadol can be used as an adjunct in epidural analgesia. Addition of tramadol to bupivacaine or ropivacaine has shown to increase the duration of postoperative analgesia than when the local anesthetics were used alone $[16,17]$. The present study is being undertaken to compare epidural Ropivacaine with Tramadol and Bupivacaine with Tramadol to evaluate the quality of analgesia, its duration of action and side effects involved for postoperative analgesia.

\section{Objective}

To compare analgesic efficacy of Bupivacaine and Ropivacaine in combination with Tramadol for postoperative epidural analgesia in terms of the quality of analgesia, its duration of action and side effects involved.

\section{Materials and Methods}

The clinical comparative study was conducted on 100 adult patients of ASA physical status I \& II in the age group of 18 to 60 years, of either sex, posted for elective major lower limb \& lower abdominal surgeries at Chigateri General Hospital, Woman \& Children Hospital, and Bapuji Hospital attached to J.J.M. Medical College, Davangere, after obtaining institutional ethical committee approval and a written informed consent from the patient. Patients were visited on the previous day of the surgery and a detailed history was taken along with general physical examination, systemic examination, airway assessment and spine examination.

\section{Inclusion Criteria}

- Patients with ASA grade I and II

- Patients with age between 18 - 60 years

- Patients posted for elective abdominal and lower limb surgeries.

\section{Exclusion Criteria}

- Patients with ASA grade III and IV

- Patient who refused to enroll in the study

- Patients posted for emergency surgeries

- Patients below 18 years and above 60 years of age

- Patients who are pregnant

Patients with known contraindications for epidural technique, uncorrected hypovolemia, consumptive 


\section{Anaesthesia \& Critical Care Medicine Journal}

coagulopathy, allergy to local anesthetics and infection at the site.

Basic laboratory investigations like - Hemoglobin, fasting / random blood glucose levels, Blood urea and serum creatinine were carried out routinely on all patients. ECG was done and chest X-ray was taken when indicated. Patients were explained about visual analogue scale. Tab. Alprazolam $0.5 \mathrm{mg}$ and Tab. Ranitidine $150 \mathrm{mg}$ orally were given on the previous night and patients were kept nil orally for 8 hours before surgery. On the day of surgery, patient was shifted into operation theatre and was made to lie supine on the operation table. Monitors were attached and baseline blood pressure, heart rate, respiratory rate and oxygen saturation were noted. IV line was secured with an 18G cannula and infusion was started with Ringer Lactate solution. The patient was put in left lateral position, parts were painted and draped. L1L2, L2-L3 and L3-L4 space suitable for respective surgery was identified. With all aseptic precautions, a skin wheal was raised at the interspace with $2 \mathrm{ml}$ of $2 \%$ lignocaine injection. The epidural space was identified using a 16G/18G Tuohy needle with loss of resistance to air technique. Then an 18G catheter was passed through the epidural needle. The needle was removed and catheter withdrawn till about 4 to 5 centimeters of catheter was in epidural space. The catheter was secured to the skin and the marking at the skin was noted. $3 \mathrm{ml}$ of $2 \%$ lignocaine with 1:2,00,000 adrenaline was given as a test dose and observed for any signs of intravascular and intrathecal injection.

After confirming correct placement of catheter in epidural space, combined spinal epidural anaesthesia (CSEA) was given; Under aseptic precautions subarachnoid block was performed by midline approach using 23 G Quincke Babcock spinal needle at L2-L3 or L3L4 intervertebral space and spinal drug was given.

No systemic analgesic drugs or opioids were given throughout the intraoperative period. Those cases where neuroaxial blockade was inadequate with the need to supplement general anaesthesia were excluded from the study. Patient's vital parameters were monitored throughout the surgery and after surgery in the postoperative ward.

When patients complained of pain, clinically correlating with visual analogue score $>5$, they were given $10 \mathrm{ml}$ of the drug epidurally by a randomized single blinded manner. 50 patients in Group BT received epidural $0.25 \%$ Bupivacaine plus Tramadol $1 \mathrm{mg} / \mathrm{kg} .50$ patients in Group RT received epidural $0.25 \%$ Ropivacaine plus Tramadol $1 \mathrm{mg} / \mathrm{kg}$. All the patients were monitored for the onset, duration and quality of analgesia. The vital parameters, motor blockade and side effects if any, were noted. The vitals parameters such as pulse rate, blood pressure and respiratory rate were recorded at 0 min, 2 mins, 5 mins, 10 mins, 20 mins, 30 mins, 45 mins, 1 hour, 2 hours, 4 hours, 6 hours, 9 hours and 12 hours time intervals. The quality of analgesia was assessed at the time when rescue analgesia was given to the patient using Verbal Response Score (VRS). Duration of analgesia is taken as the interval from time of injection of drug till reappearance of pain and requiring dose of rescue analgesia (Inj. Tramadol IV or Inj. Diclofenac IM). All the patients were observed for nausea, vomiting, respiratory depression, hypotension, bradycardia, pruritus, allergic reactions and any other side effects throughout the study period. All the patients were assessed for any motor blockade by Bromage scale and duration of blockade was noted.

The descriptive and inferential statistical analysis was carried out in the present study. The results on continuous measurements were presented on Mean \pm SD and results on categorical measurements were presented in number (\%). The significance was assessed at $5 \%$ level of significance. Student ' $\mathrm{t}$ ' test (two tailed, independent) was used to find the significance of study parameters on continuous scale between two groups (Inter group analysis) on metric parameters. Chi-square/ Fisher Exact test was used to find the significance of study parameters on categorical scale between two or more groups.

The Statistical software namely SAS 9.2, SPSS 15.0, Stata 10.1, MedCalc 9.0.1,Systat 12.0 and R environment ver.2.11.1 were used for the analysis of the data and Microsoft word and Excel were used to generate graphs, tables etc. The minimum age of the patients was $21 \mathrm{yrs}$ and maximum age was $59 \mathrm{yrs}$ with majority of the patients between 31-40yrs and 41-50yrs. In group BT, 19 (38\%) females and $31(62 \%)$ males and $20(40 \%)$ females and $30(60 \%)$ males in group RT.

The mean time for onset of analgesia in group BT was $7.16 \pm 2.06$ mins with $70 \%$ between 6-10 mins. In group $\mathrm{RT}$, the mean time was $7.60 \pm 1.63$ mins with $90 \%$ between 6-10 mins. The statistical analysis done by student ' $t$ ' test showed that, the difference between the two groups was not statistically significant. The mean duration of analgesia in group BT was $356.00 \pm 49.03$ 


\section{Anaesthesia \& Critical Care Medicine Journal}

mins with minimum duration being 270 mins and maximum being 450 mins and in group RT, the mean duration was $417.20 \pm 42.52$ mins with minimum being 310 mins and maximum being 510 mins. The majority of patients in group BT had pain relief for 300-400 mins and in group RT for more than 400 mins. The statistical analysis by student ' $\mathrm{t}$ ' test showed that duration of action in group RT was significantly more when compared to group BT with $\mathrm{p}<0.001$ Figure 1.

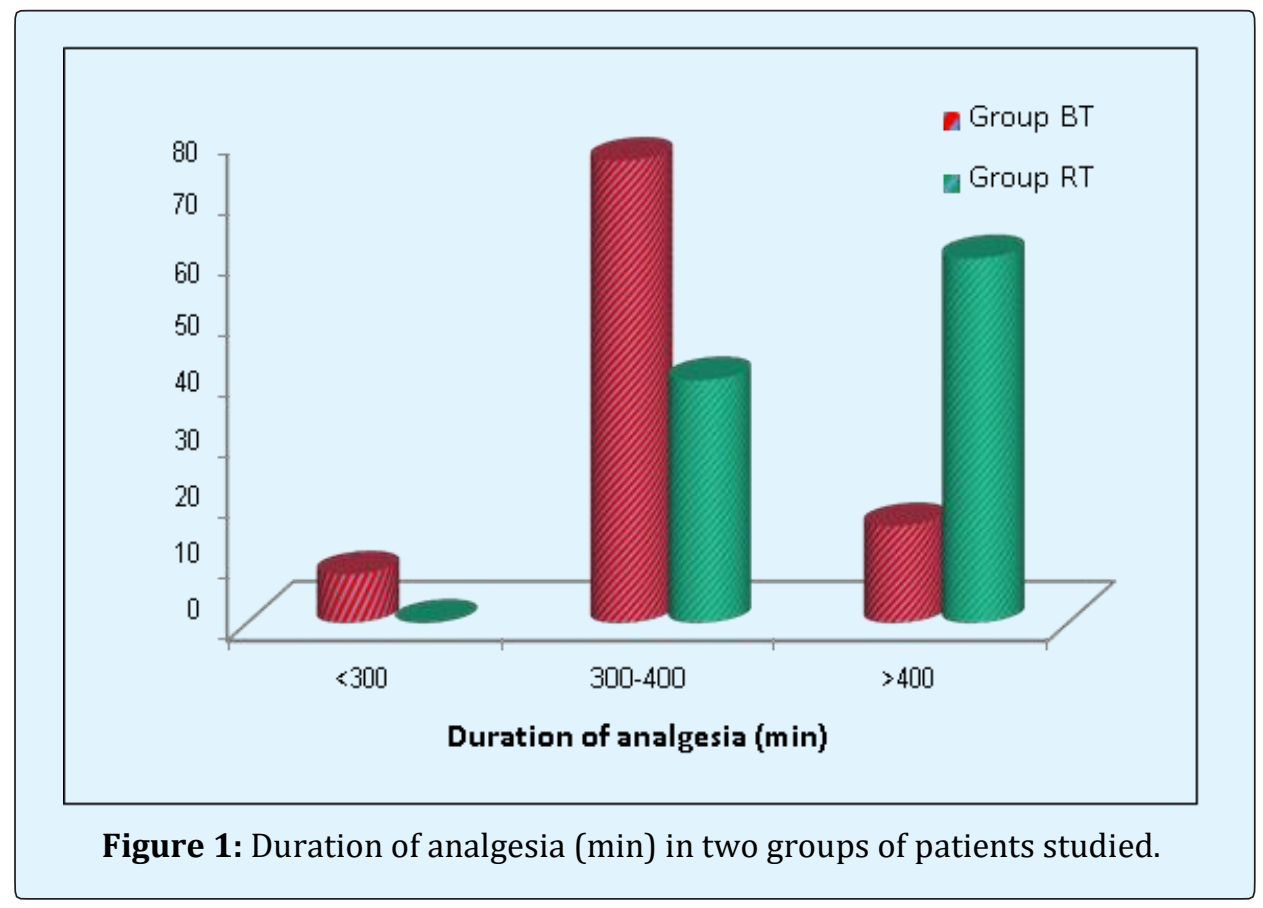

The majority of patients in both the groups had VRS score 4 (34 patients in group BT and 32 patients in group RT). The statistical analysis with student ' $t$ ' test showed that mean score between the two groups was not statistically significant.

A total 5 patients in group BT had motor blockade, among them 4 patients had grade 2 and 1 patient had grade 3 blockade with average duration lasting for 30-40 mins. None of the patients in group RT had motor blockade. The statistical analysis with Fisher Exact test showed statistical significance of $\mathrm{p}=0.056$.

In group BT, the mean pulse rate was $82.42 \pm 14.41$ beats $/ \mathrm{min}$ at $0 \mathrm{~min}$. There was fall in pulse rate starting from $76.96 \pm 14.15$ beats $/ \mathrm{min}$ at $5 \mathrm{~min}$ to $72.42 \pm 11.01$ beats/min at 1 hour and then gradually increased to $78.88 \pm 11.88$ beats $/ \mathrm{min}$ at 12 hours. In group RT the mean pulse rate was $81.08 \pm 11.46$ beats $/ \mathrm{min}$ at $0 \mathrm{mins}$, with no significant fall in pulse rate. Compared to group $\mathrm{BT}$, pulse rate in group RT was more stable.
In group BT, the mean systolic blood pressure was $123.60 \pm 13.48 \mathrm{~mm} \mathrm{Hg}$ at $0 \mathrm{~min}$. There was fall in blood pressure from 5 mins to 1 hour with minimum value being $102.00 \pm 11.20 \mathrm{~mm} \mathrm{Hg}$ at 20 mins and gradually it increased to $120.00 \pm 10.93 \mathrm{~mm} \mathrm{Hg}$ by 12 hours. In group RT, the mean systolic blood pressure was $122.10 \pm 11.83$ $\mathrm{mm} \mathrm{Hg}$ at $0 \mathrm{~min}$. There was fall in blood pressure from 5 mins to 45 mins with minimum value being $111.30 \pm 9.78$ $\mathrm{mm} \mathrm{Hg}$ at 20 mins and gradually it increased to $120.70 \pm$ $9.79 \mathrm{~mm}$ Hg by 12 hours. There was significant difference between systolic blood pressure readings of 2 groups from $10 \mathrm{~min}$ to 4 hours with $\mathrm{p}<0.001$.

In group BT, the mean diastolic blood pressure was $76.50 \pm 9.60 \mathrm{~mm} \mathrm{Hg}$ at $0 \mathrm{~min}$. There was significant fall in blood pressure from 5 mins to 2 hours with minimum value being $64.60 \pm 7.68 \mathrm{~mm} \mathrm{Hg}$ at $10 \mathrm{~min}$ and gradually it increased to $76.20 \pm 7.53 \mathrm{~mm} \mathrm{Hg}$ by 12 hours. In group $\mathrm{RT}$, the mean diastolic blood pressure was $78.80 \pm 8.12$ $\mathrm{mm} \mathrm{Hg}$ at $0 \mathrm{~min}$. There was fall in blood pressure from 5 mins to 1 hours with minimum value being $70.40 \pm 6.76$ $\mathrm{mm} \mathrm{Hg}$ at 10 mins and gradually it increased to $78.20 \pm$ 


\section{Anaesthesia \& Critical Care Medicine Journal}

$6.98 \mathrm{~mm} \mathrm{Hg}$ by 12 hours. There was significant difference between diastolic blood pressure readings of 2 groups from 10 mins to 4 hours with $\mathrm{p}<0.001$.

There was no significant change in respiratory rate between both the groups and respiratory rate of the 2 groups were comparable at all the time intervals.

No significant side effects were noted in both the groups. 2 patients in group BT and 1 patient in group RT had vomiting and 1 patient in group RT had nausea. The statistical analysis done by fisher exact test showed that, the difference in side effects between the two groups was not significant.

\section{Discussion}

The goals of post-operative pain management are to relieve suffering, achieve early mobilization after surgery, reduce length of hospital stay and achieve patient satisfaction. Management of post-operative pain still poses a lot of challenges to anesthetists. Various modalities have been tried to relieve the post-operative pain. Epidural analgesia is now accepted as the prime modality of pain relief following lower abdominal and lower limb surgeries.

This study attempted to assess the efficacy of epidural Bupivacaine plus Tramadol and Ropivacaine plus Tramadol in the management of immediate postoperative analgesia in abdominal and lower limb surgeries. Fifty patients of ASA grade I and II, belonging to age between 18 - 60 years, of which majority were in between 31-40 years and 41-50 years of age, undergoing elective abdominal and lower limb surgeries were taken into each of the two groups.

There is a statistically significant difference in the duration of analgesia between the 2 groups. The duration of analgesia in group RT was significantly longer than in group BT with $\mathrm{p}<0.001$. A similar finding was observed by Doctor TP, et al. [18] who conducted a study to compare the effectiveness of Inj. Ropivacaine (0.2 or $0.25 \%)$ or Inj. Bupivacaine $(0.25 \%)$ with fentanyl in caudal block for intra and postoperative analgesia. The duration of analgesia was slightly more with the Ropivacaine fentanyl (6.1 hrs) as compared to 5.6hrs in bupivacaine fentanyl group but difference was statistically insignificant.

There is no significant difference between the 2 groups with regard to onset of analgesia or quality of analgesia. Chudasama P, et al. [19] conducted a study to compare $0.5 \%$ bupivacaine and $0.75 \%$ ropivacaine for postoperative analgesia and found no significant difference in time of onset of analgesia between two groups. Berti $\mathrm{M}$, et al. [20] studied about epidural ropivacaine $0.2 \%+2 \mu \mathrm{g} / \mathrm{ml}$ fentanyl and bupivacaine $0.125 \%+2 \mu \mathrm{g} / \mathrm{ml}$ fentanyl given for patients after major abdominal surgery. They observed no differences between groups in the degree of pain relief at any of the measurement times, and the number of rescue analgesics required was similar in the two groups. Bawdane $\mathrm{K}$, et al. [21] compared $0.1 \%$ ropivacaine with fentanyl $2 \mu \mathrm{g} / \mathrm{mL}$ to $0.1 \%$ bupivacaine with fentanyl $2 \mu \mathrm{g} / \mathrm{ml}$ for epidural analgesia in labour and showed similar pain scores for bupivacaine and ropivacaine group in the first stage and second stage of labor. Total 4 patients developed motor blockade in group BT; majority of patients had grade 2 block ranging from $30-40 \mathrm{~min}$ duration. None of the patients in group RT had motor blockade. Finegold H, et al. [22] conducted a study to compare analgesic efficacies of $0.1 \%$ ropivacaine-fentanyl and $0.125 \%$ bupivacainefentanyl infusions for labour epidural analgesia and found that at least $80 \%$ of patients in the ropivacaine group had no demonstrable motor block after the first hour compared with only $55 \%$ of patients who were given bupivacaine. Berti M, et al. [20] compared ropivacaine $0.2 \%+2 \mu \mathrm{g} / \mathrm{ml}$ fentanyl and bupivacaine $0.125 \%+2 \mu \mathrm{g} / \mathrm{ml}$ fentanyl for patient supplemented epidural analgesia after major abdominal surgery but found no difference in the incidence of motor blockade. The basal pulse rate, diastolic and systolic blood pressure and respiratory rate between both the groups were comparable. There was fall in pulse rate in group BT, but in group RT there was no significant fall. There was significantly more fall in both systolic and diastolic blood pressures in group BT when compared with group RT particularly from 10 mins to 4 hours with $\mathrm{p}<0.001$. The two groups did not differ in respiratory rate at any time interval. The changes in respiratory rate were insignificant between the two groups.

\section{Conclusion}

Tramadol is a cheaper alternative to other opioids and can be safely used along with local anesthetics for epidural analgesia. Ropivacaine with tramadol for epidural postoperative analgesia gave equal and effective analgesia, but for longer duration and with minimal cardiovascular depression when compared to bupivacaine plus tramadol. No difference was seen in motor blockade and side effects between the two groups. 


\section{Anaesthesia \& Critical Care Medicine Journal}

\section{References}

1. Liu S, Carpenter RL, Neal JM (1995) Epidural anaesthesia and analgesia. Their role in postoperative outcome. Anaesthesiology 82(6): 1474-1506.

2. Whiteside R, Jones D, Bignell S, Lang C, Lo SK (2000) Epidural ropivacaine with fentanyl following major gynaecological surgery: the effect of volume and concentration on pain relief and motor impairment. Br J Anaesth 84(6): 720-724.

3. Pouzeratte Y, Delay JM, Brunat G, Boccara G, Vergne C, et al. (2001) Patient- controlled epidural analgesia after abdominal surgery: Ropivacaine versus bupivacaine. Anesth Analg 93(6): 1587-192.

4. Lee WK, Yu KL, Tang CS, Lee LS, Fang HT (2003) Ropivacane $0.1 \%$ with or without fentanyl for epidural postoperative analgesia: a randomized, double-blind comparison. Kaohsiung J Med Sci 19(9): 458-463.

5. De Cosmo G, Primeri P, Adducci E, Fiorenti M, Beccia G (2004) Epidural analgesia in abdominal surgery: $0.2 \%$ ropivacaine with sufentanil. Minerva Anestesiol 70(6): 503-508.

6. Prakash S, Tyagi R, Gogia AR, Singh R, Prakash S (2006) Efficacy of three doses of tramadol with bupivacaine for caudal analgesia in paediatric inguinal herniotomy. Br J Anaesth 97(3): 385-388.

7. Scott DA (2001) Ropivacaine for postoperative epidural analgesia. Techniques in Regional Anesthesia and Pain Management 5(2): 64-69.

8. Brodner G, Mertes N, Van Aken H, Pogatzki E, Buerkle $\mathrm{H}$, et al. (1999) Epidural analgesia with local anesthetics after abdominal surgery: earlier motor recovery with $0.2 \%$ ropivacaine than $0.175 \%$ bupivacaine. Anesth Analg 88(1): 128-133.

9. Bertini L, Mancini S, Di Benedetto P, Ciaschi A, Martini 0 , et al. (2001) Postoperative analgesia by combined continuous infusion and patient- controlled epidural analgesia (PCEA) following hip replacement: ropivacaine versus bupivacaine. Acta Anaesthesiol Scand 45(6): 782- 785.

10. Hodgson PS, Liu SS (2001) A comparison of ropivacaine with fentanyl to bupivacaine with

Shilpashri AM, et al. Postoperative Epidural Analgesia between $0.25 \%$ Ropivacaine Plus Tramadol and $0.25 \%$ Bupivacaine Plus Tramadol in Abdominal and Lower Limb Surgeries - A Comparative Study. Anaesth Critic Care Med J 2019, 4(2): 000152. fentanyl for postoperative patient-controlled epidural analgesia. Anesth Analg 92(4): 1024-1028.

11. Kanai A, Nakahara R, Okamoto H, Hoka S (2003) Postoperative analgesia using continuous lumbar epidural infusion of ropivacaine in comparison with bupivacaine. Masui 52(8): 832-839.

12. Negri De, Pasquale, Ivani Giorgio, Tirri Tiziana, Modano Pasqualina, et al. (2004) A Comparison of Epidural Bupivacaine, Levobupivacaine, and Ropivacaine on Postoperative Analgesia and Motor Blockade. Anesth Analg 99(1): 45-48.

13. Wan XH, Huang QQ, Su MX, Wan LJ, Huang HQ (2006) Security evaluation of bupivacaine, ropivacaine combined with fentanyl in postoperative continuous epiduralanalgesia. Zhonghua Wai Ke Za Zhi 44(17): 1200-1202.

14. Malam P, Malam R, Shah B, Yatin R, Patel S, et al. (2016) Comparision of analgesic effect of epidural Ropivacaine $(0.2 \%)$ and Ropivacaine $(0.2 \%)$ with Fentanyl $(4 \mathrm{mcg} / \mathrm{ml})$ in postoperative patient of total knee replacement surgery. IJPSR 7(6): 2546-2557.

15. Singh AP, Singh D, Singh Y, Jain G (2015) Postoperative analgesic efficacy of epidural tramadol as adjutant to ropivacaine in adult upper abdominal surgeries. Anesth Essays Res 9(3): 369-373.

16. Saxena D, Sanwatsarkar S, Dixit A, Arya B (2017) Comparative study of duration of analgesia with epidural bupivacaine and bupivacaine with tramadol in lower limb surgeries. International Journal of Research in Medical Sciences 5(5): 2003.

17. Duman A, Kesriklioglu A, Ogun CO, Duman I, Okesli S (2001) Addition of tramadol to bupivacaine for epidural analgesia in transurethral prostate resections. European Journal of Anaesthesiology 18: 83.

18. Doctor TP, Divyang DB, Abraham L, Shah N, Chadha IA, et al. (2013) Comparison of ropivacaine and bupivacaine with fentanyl for caudal epidural in pediatric surgery. Anesth Essays Res 7(2): 212-215.

19. Chudasama P, Prajeesh Nambiar P, Prashant Sorathiya, Shaunak Swaminarayan, Samira Parikh, et al. (2013) Comparison of epidural ropivacaine and bupivacaine for lower limb surgery. NJIRM 4(3): 115120. 


\section{Anaesthesia \& Critical Care Medicine Journal}

20. Berti M, Casati A, Fanelli G, Albertin A, Palmisano S, et al. (2000) $0.2 \%$ ropivacaine with or without fentanyl for patient-controlled epidural analgesia after major abdominal surgery: a double-blind study. J Clin Anesth 12(4): 292-297.

21. Bawdane KD, Magar JD, Tendolkar BA (2016) Double blind comparison of combination of $0.1 \%$ ropivacaine and fentanyl to combination of $0.1 \%$ bupivacaine and fentanyl for extradural analgesia in labour. J Anaesthesiol Clin Pharmacol 32(1): 38-43.

22. Finegold $H$, Mandell Gordon, Ramanathan Sivam (2000) Comparison of ropivacaine $0.1 \%$ - fentanyl and bupivacaine $0.125 \%$ - fentanyl infusion for epidural labour analgesia. Can J Anaesth 47(8): 740745. 